\title{
Is emigration worth the trouble? Satisfaction with life, group identifications, perceived discrimination, and socio-economic status of immigrants and stayers
}

\author{
Eugene Tartakovsky ${ }^{\mathrm{a}, *}$, Eduard Patrakov ${ }^{\mathrm{b}}$, Marina Nikulina ${ }^{\mathrm{c}}$ \\ ${ }^{a}$ The Bob Shapell School of Social Work, Tel-Aviv University, P.O.B. 39040, Tel-Aviv 69978, Israel \\ ${ }^{\mathrm{b}}$ Ural Federal University, Yekaterinburg, Russian Federation \\ ${ }^{\mathrm{c}}$ The All-Russian State University of Justice (RLA of the Ministry of Justice of Russia) of Rostov Law Institute (Branch), Rostov, Russian Federation
}

\section{A R T I C L E I N F O}

\section{Keywords:}

Immigrants and stayers

Satisfaction with life

Morbidity and salutary immigration

hypotheses

Group identifications

Perceived discrimination

The rejection-disidentification and rejectionidentification models

\begin{abstract}
A B S T R A C T
In the present study, we examined satisfaction with life (SWL), group identifications, perceived discrimination, and socio-economic status among immigrants and stayers. The study had two main objectives: 1) to test the morbidity and salutary hypotheses of immigration by comparing the psycho-social characteristics of immigrants and stayers; 2) to test a resource model of wellbeing among immigrants and stayers by investigating the effect of different resources and stressors on SWL. The study was conducted using a random representative sample of firstgeneration immigrants from the Former Soviet Union to Israel $(n=400)$ and a not-random large and geographically dispersed sample of Jews staying in Russia $(n=935)$. The comparison of immigrants and stayers revealed that immigration is a mixed blessing, salutary in some aspects and onerous in others. In general, immigrants were more satisfied with their life than stayers. In addition, identification with the country of residence was stronger among immigrants than stayers. However, immigrants reported a higher level of perceived discrimination, and their socio-economic status was lower than that of stayers. Socio-economic status, identification with the country of residence, and perceived discrimination were directly connected to SWL among immigrants and stayers. In addition, among stayers, identification with the ethnic minority group was connected to SWL, while among immigrants, identification with the country of origin was not connected to SWL. Socio-economic status and perceived discrimination also affected SWL indirectly, through their connections to identification with the country of residence among immigrants and stayers and through their connection to ethnic identification among stayers.
\end{abstract}

Numerous studies have focused on the psychological well-being of immigrants (Bak-Klimek, Karatzias, Elliott, \& Maclean, 2015; Baltatescu, 2005), and some of the studies have compared immigrants with the population in the receiving country and with other immigrant groups (Baltatescu, 2005, Berry \& Hou, 2017; Bobowik, Martinovic, Basabe, Barsties, \& Wachter, 2017). These studies have been essential for advancing our understanding of immigration processes. However, they share a disadvantage of "comparing apples to oranges" because immigrants and their hosts have a different past that may predetermine their personal and social resources, perception of environmental stressors, coping styles and, thus, affect their psychological well-being (Hendriks, 2015).

In the present study, we aimed to advance the existing knowledge by comparing immigrants with stayers ("apples to apples that fell

\footnotetext{
* Corresponding author.

E-mail addresses: evgenyt@tauex.tau.ac.il (E. Tartakovsky), eduardp@mail.ru (E. Patrakov), nikulina_marina@mail.ru (M. Nikulina).
} 
from the tree"). To do so, we examined satisfaction with life (SWL), group identifications, perceived discrimination, and socioeconomic status among Jewish immigrants from the Former Soviet Union (FSU) in Israel and Jews and their relatives living in Russia. Choosing these populations for the study provided us with several unique research opportunities. First, the two groups share a common past; therefore, the found differences may be with greater certainty attributed to the effect of emigration and adjustment to the new country (Hendriks, 2015). Second, according to the Israeli Law of Return, all diaspora Jews and their relatives are eligible to immigrate to Israel (The State of Israel, 1970). Therefore, any differences between immigrants and stayers found in the present study cannot be attributed to the selection criteria dictated by the receiving country (age, education, occupation, and language mastery), as has been possible in all previous studies comparing immigrants and stayers. Third, a common feature of the immigrants and stayers in the present study is that both groups are minorities in their country. Jews constitute an ethnic minority in Russia, and immigrants from the FSU, while formally joining the majority group in Israel, constitute a distinctive ethnocultural group and are often called "Russians" in informal discourse (Tartakovsky \& Walsh, 2019). The minority status of both immigrants and stayers permitted to compare them not only in SWL and socio-economic status but also in group identifications and perceived discrimination.

\section{Comparing well-being in immigrant and non-immigrant populations}

There are two main hypotheses related to the well-being of immigrants: the morbidity and salutary hypotheses. The immigration morbidity hypothesis assumes that immigration is stressful and, therefore, causes a decrease in psychological well-being and may be even traumatic for immigrants (Mirsky, Kohn, Levav, Grinshpoon, \& Ponizovsky, 2008). Researchers attribute the morbidity of immigration to two main factors: losses resulting from leaving the country of origin (e.g., loss of mother tongue and the related cultural environment, physical environment, and social connections) and acculturative stress in the receiving country (e.g., difficulties related to mastering a new language, financial strains, and building new social networks) (Baltatescu, 2005; Wei et al., 2007). However, other researchers adhere to the salutary hypothesis, stressing the potentially positive aspects of immigration related to the opportunity for immigrants to enjoy the benefits of a more developed and democratic receiving country. The potential benefits of immigrants in the new country may be economical (e.g., higher earnings and welfare services) or political (e.g., political freedom and protection of human rights) (Baltatescu, 2005; Massey, 2002). Surprisingly, the psychological literature on the immigrants' well-being rarely accounts for the salutary immigration hypothesis.

Most empirical studies that compared immigrants with locals in the receiving country found that immigrants reported lower levels of psychological well-being and higher distress levels than the majority population (Baltatescu, 2005; Bartram, 2011; Hendriks, 2015; Mirsky et al., 2008). Researchers usually ascribed these findings to a worse financial situation, lower social capital, and immigrants' discrimination (Hendriks, 2015; Mirsky et al., 2008). However, immigrants usually arrive from countries with a lower level of economic development and a lower level of psychological well-being, which may explain (at least partly) the immigrants' lower well-being in the receiving country (Hendriks, 2015). Indeed, the rare studies that have focused on the groups that immigrated from more to less developed countries, or from more to less happy countries, found that these immigrants reported higher well-being than locals (Hendriks, 2015). ${ }^{1}$

There are only about a dozen studies that have compared the well-being of immigrants with the population in their country of origin, and their findings are inconsistent across countries and indexes of well-being used for comparison (Hendriks, 2015; Lönnqvist, Leikas, Mähönen, \& Jasinskaja-Lahti, 2015). In a comprehensive meta-analysis of studies comparing immigrants with stayers, five studies found a higher level of well-being among immigrants, four found lower well-being among immigrants, and two studies found no difference (Hendriks, 2015). However, all the studies comparing immigrants and stayers used relatively small and non-representative samples. Moreover, as mentioned above, the sociodemographic characteristics of immigrants in those studies were different from those of stayers due to selective emigration criteria.

In the present study, we tested the salutary $v s$. morbidity hypothesis comparing Jewish immigrants from the Former Soviet Union to Israel with Jews who stayed in Russia. Several factors may account for a higher level of psychological well-being of immigrants from the FSU in Israel compared to Jews living in Russia. The first is related to a higher level of socio-economic development in Israel compared to Russia (UNDP, United Nations Development Programme, 2019). The second is the relatively benign conditions existing for diaspora immigrants in Israel that include receiving full citizen rights immediately upon arrival and financial support from governmental and non-governmental organizations (Amit, 2012; Raijman \& Geffen, 2018; Tartakovsky \& Walsh, 2019). Finally, Israeli democracy and the opportunity to practice one's ethnic culture and religion may also contribute to the immigrants' psychological well-being.

On the other hand, the difficulties of immigrants from the FSU in Israel have been well documented in previous studies. They include difficulties in learning Hebrew, understanding and managing the Israeli education system, getting one's professional credentials recognized, and finding a job in a relatively small Israeli job market (Amit, 2012; Bartram, 2011; Chachashvili-Bolotin, 2011;

\footnotetext{
1 There is also a phenomenon called "the immigrant paradox" that relates to the following findings: 1) some groups of immigrants demonstrate less incidents of risky behavior (e.g., substance use, school truancy, and crimes) and have fewer health problems than the locals; 2) among some immigrant groups, time in the receiving country is positively correlated with social problems, and 3) second-generation immigrants may demonstrate more risky behavior than first-generation immigrants (Salas-Wright, Vaughn, Schwartz, \& Córdova, 2016). However, the immigrant paradox was mostly found among adolescents, and it was not demonstrated regarding psychological well-being (Bowe, 2017). In addition, it was found mostly in the US, and its existence was rarely confirmed in Europe (Sam, Vedder, Liebkind, \& Virta, 2008). In Israel, evidence for immigrant paradox was found for immigrant adolescents from Ethiopia, but not from the FSU (Kahan-Strawczynski et al., 2010).
} 
Kahan-Strawczynski, Levi, \& Konstantinov, 2010; Silbereisen, Titzmann, \& Shavit, 2016). In addition, researchers note the ambivalent attitude of local Israelis towards immigrants (Tartakovsky \& Walsh, 2019) and tension that often exists between the two groups (Kahan-Strawczynski et al., 2010).

Given the complexity of immigration processes, we could not predict whether immigration is salutogenic or pathogenic for immigrants from the FSU in Israel. To answer this question, we compared satisfaction with life among immigrants and stayers., We also compared the two groups in several variables that may be considered as either resources or stressors potentially affecting the individuals' well-being: socio-economic status, perceived discrimination, and group identifications.

\section{A resource model of well-being}

Several theoretical models strive to explain the effect of different variables on psychological well-being (Lyubomirsky, Sheldon, \& Schkade, 2005; Myers, 2000). In the present study, we applied a resource model of well-being (Hobfoll, 2002), which assumes that resources, i.e., entities that are either valued in their own right (e.g., self-esteem, close attachments, health, and inner peace) or act as a means to obtain valued ends (e.g., money and social support), are pivotal for well-being. Resources may be divided into tangible (e.g., money and housing), social (e.g., social connections and social support), and affective-cognitive (e.g., self-esteem and optimism) (Hobfoll, 2002; Lyubomirsky et al., 2005; Myers, 2000). Some researchers consider not only resources but also stressors as factors draining the resources and thus negatively affecting psychological well-being. Furthermore, resource models assume that the stressogenic effect of stressors, i.e., their number and the perceived severity, may depend (inversely) on the individual's resources (Hobfoll, 2002). In what follows, we review tangible and social resources and stressors relevant to immigrants and ethnic minorities. We did not include affective-cognitive resources in the present study because their effect on psychological well-being is supposed to be universal and not specific to the situation of immigration (Hobfoll, 2002; Lyubomirsky et al., 2005; Myers, 2000).

\section{Tangible Resources}

Considering tangible resources, researchers focused on socio-economic status (SES) that includes education, occupational status, income, and wealth (Sobel, Semyonov, \& Lewin-Epstein, 2019). Studies conducted in different countries have demonstrated that a higher SES is associated with higher psychological well-being (Barger, Donoho, \& Wayment, 2009; Pinquart \& Sörensen, 2000; Sobel et al., 2019). However, some ethno-cultural groups reported a high level of well-being despite their precarious socio-economic conditions (Lyubomirsky et al., 2005; Myers, 2000).

Studies conducted in different immigrant and ethnic minority groups found a positive effect of SES on the well-being; however, most of these studies focused on the role of income (Barger et al., 2009; Bartram, 2011; Berry \& Hou, 2017; Calvo \& Cheung, 2018; Lönnqvist et al., 2015; Raijman \& Geffen, 2018). In the present study, we investigated the effects of two other elements of SES on well-being - education and occupation. We did not include income and wealth in our study because comparing immigrants and stayers in these variables was difficult due to the differences in economic systems and costs of living in the two countries (Sobel et al., 2019). Following the results of previous studies (Barger et al., 2009), we hypothesized that education and occupational status would directly affect SWL among immigrants and stayers (H1).

\section{Social Resources}

Social resources are essential for one's psychological well-being (Hobfoll, 2002; Lyubomirsky et al., 2005; Myers, 2000), and identification with a group facilitates the individuals' access to social resources associated with this group (Berry, 2017). Among ethnic minorities, group identifications include identification with the country of residence and identification with the ethnic minority group. Among immigrants, the system of group identifications is even more complex. It includes identification with fellow immigrants, identification with the country of origin, and identification with the receiving country (Amit, 2012; Berry \& Hou, 2017; Ward, Gale, Staerklé, \& Stuart, 2018). For immigrants who were ethnic minorities in their country of origin (e.g., Jews), the identification system also includes identification with the ethnic minority group (Tartakovsky, Patrakov, \& Nikulina, 2017; Walsh \& Tartakovsky, 2011). Each of these social entities may provide social support and, therefore, constitutes a social resource promoting psychological well-being. Therefore, acculturation theory assumes that those immigrants and ethnic minorities who identify strongly with both dominant and non-dominant groups (i.e., apply the integration acculturation strategy) may enjoy the maximum social support and ensure the highest level of psychological well-being (Berry, 2017). ${ }^{2}$

Most studies that used the categorical approach to acculturation found that immigrants and ethnic minorities who adhered to the integration acculturation strategy reported the highest social adjustment and psychological well-being (Berry \& Hou, 2017; Phinney, Horenczyk, Liebkind, \& Vedder, 2001). However, the results of empirical studies that used the dimensional approach, i.e., tested separately the connections between the dominant and non-dominant group identifications with psychological well-being, have been less conclusive. Most studies have found a positive connection between identification with the country of residence and psychological well-being among both immigrants and ethnic minorities (Amit, 2012; Neto, 2001). In addition, most studies conducted among ethnic minorities found a positive connection between ethnic identification and psychological well-being (Smith \& Silva, 2011). However,

\footnotetext{
${ }^{2}$ In the present study, we did not examine the immigrants' Jewish identification and their identification with the fellow immigrants. However, a previous study (Walsh \& Tartakovsky, 2011) found a positive effect of these variables on psychological well-being.
} 
several studies conducted among immigrants in Europe (Neto, 2001) and Israel (Amit, 2012; Walsh \& Tartakovsky, 2011) have not found a connection between identification with the country of origin and psychological well-being.

In the present study, we assumed that identification with the country of residence constitutes a social resource for immigrants and ethnic minorities. Therefore, we hypothesized that a higher level of identification with Israel among immigrants and with Russia among Jews living in Russia would be associated with a higher level of SWL in these populations (H2). However, we assumed that while the Jewish community in Russia is an important source of social support for its members, social support provided by the country of origin is probably too weak to affect the psychological well-being of immigrants. Therefore, we hypothesized a positive connection between ethnic identification and SWL among Jews living in Russia; however, we did not expect to find a connection between SWL and identification with the country of origin among immigrants (H3).

\section{Social stressors: perceived discrimination}

Researchers consider discrimination to be one of the main stressors for immigrants and ethnic minorities (Berry, 2017; Ward et al., 2018). It is assumed that discrimination diminishes social support received by immigrants and ethnic minorities from the larger society and harms their sense of self-esteem and mastery (Berry \& Hou, 2017). Consequently, perceived discrimination was associated with lower well-being in all immigrant and ethnic minority groups (Berry \& Hou, 2017; Kirmanoglu \& Baslevent, 2014; Raijman \& Geffen, 2018). Therefore, in the present study, we hypothesized a direct negative effect of perceived discrimination on SWL among immigrants and stayers (H4).

\section{Indirect effects of perceived discrimination and SES on SWL}

A resource model of well-being assumes that resources and stressors may affect well-being indirectly, through their connections with other resources and stressors (Hobfoll, 2002). Based on this assumption, in the present study, we assumed that perceived discrimination and SES might affect SWL indirectly, through their connection with group identifications. Below, we justify this assumption.

Two models - the rejection-disidentification and rejection-identification models - have been suggested for explaining the connection between perceived discrimination and group identifications. According to the rejection-disidentification model, members of minority groups react to discrimination by distancing themselves from the dominant group and decreasing their identification with the country of residence. The rejection-identification model assumes that, in addition to disidentification from the country of residence, discrimination leads to the strengthening of identification with the minority group (Eccleston \& Major, 2006; Jasinskaja-Lahti, Liebkind, \& Solheim, 2009).

Empirical studies have found a robust negative effect of discrimination on the identification with the country of residence among both immigrants and ethnic minorities, while empirical tests of the rejection-identification model yielded inconsistent results (Bobowik et al., 2017; Jasinskaja-Lahti et al., 2009; Verkuyten \& Yildiz, 2007). Therefore, in the present study, we hypothesized that perceived discrimination is negatively connected to identification with Israel among immigrants and identification with Russia among stayers. Moreover, as stated above, we hypothesized that identification with the country of residence is positively connected to psychological well-being. Therefore, we hypothesized that perceived discrimination would negatively affect SWL indirectly, through its negative connection to identification with the country of residence among both immigrants and stayers (H5). We did not formulate a hypothesis regarding the indirect effect of perceived discrimination on SWL through its connection to identification with the country of origin for immigrants and with Jews in Russia for stayers because the results of previous studies testing the rejection-identification model were inconclusive. However, we examined this effect among both immigrants and stayers.

Finally, we assumed that people living in a specific country, including immigrants and ethnic minorities, may associate their socioeconomic conditions with the general economic and political situation in the country. Therefore, those whose socio-economic

Table 1

Sociodemographic Characteristics of the Samples.

\begin{tabular}{llll}
\hline Sociodemographic characteristics & Immigrants from the FSU to Israel; $\mathrm{n}=400$ & Jews in Russia; $\mathrm{n}=935$ & Analysis of the difference \\
\hline Age, $M(S D)$ & $47.5(14.1)$ & $39.6(11.5)$ & $t(1333)=10.6, p<.001$ \\
The level of religiosity, $M(S D)$ & $1.66(.84)$ & $2.09(.89)$ & $t(1316)=8.20, p<.001$ \\
Gender & $46 \%$ & $44 \%$ & $\chi^{2}(1)=.557, p=.458$ \\
Family status & $76 \%$ & $74 \%$ & $\chi^{2}(1)=.051, p=.478$ \\
Education & $72 \%$ & $86 \%$ & $\chi^{2}(1)=33.7, p<.001$ \\
Religious affiliation & $39 \%, 58 \%, 3 \%$ & $41 \%, 43 \%, 16 \%$ & $\chi^{2}(2)=55.7, p<.001$ \\
Jewish ethicity & $82 \%$ & $58 \%$ & $\chi^{2}(1)=74.9, p<.001$ \\
Occupational status & $15 \%, 14 \%, 14 \%, 19 \%, 33 \%, 2 \%, 3 \%$ & $12 \%, 1 \%, 6 \%, 18 \%, 50 \%, 8 \%, 5 \%$ & $\chi^{2}(6)=158, p<.001$ \\
Age of arrival; $M(S D) ;$ [range] & $28.4(12.7) ;[2 ; 65]$ & & \\
Years in Israel; $M(S D) ;$ [range] & $19.1(7.79) ;[1 ; 30]$ & & \\
\hline
\end{tabular}

Note: Gender: the proportion of males, \%. Family status: married or living with a partner, \%. Education: tertiary, \%. Religious affiliation: nonaffiliated, Judaism, other religion, \%. Religiosity: on a 5-point scale from 1 - atheist to 5 - orthodox. Jewish ethnicity: having a Jewish maternal grandmother, \%. Occupational status: not working, manual non-qualified work, qualified manual work, clerical work, professional work, managerial work, own business, $\%$. 
conditions are better may perceive their country of residence more positively and, therefore, identify stronger with this country. Thus, we hypothesized that SES might affect identification with the country of residence and, through it, indirectly affect SWL among both immigrants and stayers (H6).

\section{Method}

\section{Samples}

Four hundred immigrants from the FSU in Israel and 935 Jews and their relatives living in Russia took part in the present study. Table 1 presents the sociodemographic characteristics of the samples. Both samples were nearly balanced in gender (about $45 \%$ male), and about $75 \%$ of the participants in both samples were married or living with a partner. However, the immigrant sample was older than the stayers (47.5 vs. 39.6). The participants in both samples were highly educated; although, a higher proportion of Jews in Russia had tertiary education than the immigrants ( $86 \%$ vs. $72 \%$ ). A high proportion of participants in both samples had a high occupational status, being either professionals, managers, or business persons; however, there were more such people among Jews living in Russia than among immigrants (63\% vs. $38 \%$ ). On the other hand, more immigrants held manual jobs ( $28 \%$ vs. $7 \%$ ). The proportion of Jews as defined by Jewish religious law (i.e., having a Jewish maternal grandmother) was higher among immigrants (82\% vs. $58 \%$ ). Finally, religiosity was lower among immigrants (1.66 vs. 2.09 on a 5-point scale).

\section{Procedure}

Participation in the research was voluntary, and participants did not receive compensation for completing the questionnaires. Informed consent was obtained from all participants. The questionnaires were in Russian. The response rate was about $65 \%$ in both samples.

Immigrants. The immigrant sample was a random representative sample of adult immigrants who arrived from the FSU to Israel since 1989. The sample was built using stratified geographical sampling within the internationally recognized borders of Israel. Completion of questionnaires was done face to face in the participant's home. Data was collected by the PORI research institute.

Stayers. The study among Jews living in Russia was conducted in five metropolitan areas: Moscow, St. Petersburg, Yekaterinburg, Rostov, and Kazan. The study questionnaires were distributed by research associates living in the metropolitan areas through social networks, in the Jewish community and religious organizations, and through the researchers' acquaintances in face-to-face interviews, by e-mail, and using electronic questionnaires. Adults eligible for immigration to Israel under the Law of Return were asked to complete the questionnaires anonymously. Individuals holding foreign citizenship (i.e., those who emigrated and then returned to Russia) were excluded from the study.

\section{Instruments}

Satisfaction with Life. Satisfaction with life (SWL) was measured by the Satisfaction with Life Scale (Diener, Emmos, Larsen, \& Griffin, 1985). It is a 5-item scale asking respondents to assess their agreement with the items on a 7-point scale, from 1 -completely disagree to 7 - completely agree. Internal consistency of the scale was high among both immigrants (Cronbach's $\alpha=.93$ ) and stayers (Cronbach's $\alpha=.88$ ).

Group identifications. All group identifications were measured using a scale developed by Roccas (2003). The scale is comprised of the following four items (the examples are for identification with Jews): "Being Jewish is an important part of my self-definition"; "When I talk about Jews, I say 'we' and not 'they'"; "When Jews are criticized, I take it personally"; "It is important for me to think about myself as a Jew." The participants evaluated each item on a 5-point scale, from 1 (do not agree at all) to 5 (fully agree). For measuring identifications with the country, the word Jews was interchanged with Russians, Israelis, or citizens of my country of origin. The scale demonstrated high internal consistency in the immigrant population for identification with Israel (Cronbach's $\alpha=.91$ ) and the country of origin (Cronbach's $\alpha=.89$ ), and in the Jewish population in Russia for identification with Russia (Cronbach's $\alpha=.88$ ) and Jews (Cronbach's $\alpha=.90)$.

Perceived discrimination. Perceived discrimination was measured by the Discrimination Questionnaire (Phinney, Madden, \& Santos, 1998). The questionnaire consists of 12 items measuring the ethnic minority members' suffering due to negative attitudes of the majority population. Item example: "I feel that I am not wanted in Israeli society because I am an immigrant from the FSU." The participants evaluated each item on a 5-point scale, from 1 (do not agree at all) to 5 (fully agree). The scale had high internal consistency in the immigrant population (Cronbach's $\alpha=.93$ ) and among Jews living in Russia (Cronbach's $\alpha=.92$ ).

Occupational status. Occupational status was measured using a one-item scale developed by Stevens and Featherman (1981). The scale included different occupations ranging from 1 to 7 : not working, non-qualified manual work, qualified manual work, clerical work, professional work, managerial work, and business. The respondents reported their last occupational status.

Education. The level of education was measured using a one-item 6-point scale on which the participants indicated their highest achieved level of education, from 1 - elementary school to 6 -doctorate. 


\section{Results}

\section{Descriptive analysis}

Before testing for differences between immigrants and stayers, we tested for measurement invariance of three scales: SWL, perceived discrimination, and identification with the country of residence. The details of the tests are provided in the Supplemental Materials. Configural, metric, and partial scalar invariance was demonstrated for SWL and perceived discrimination. However, only configural and metric invariance were demonstrated for identification with the country of residence.

Table 2 presents bivariate correlations between the variables in the study, as well as their means and standard deviations, for immigrants and stayers. As data presented in Table 1 indicate, immigrants and stayers differed in several sociodemographic variables. Therefore, the two groups were compared using a general linear model that included the following five sociodemographic variables as covariates: age, education, occupational status, Jewish ethnicity, and the level of religiosity (IBM SPSS Software, 2019). Univariate tests controlling for socio-demographic variables demonstrated that immigrants reported a significantly higher level of SWL than stayers: $M(S D)_{\mathrm{IM}}=4.08(1.24) v s . M(S D)_{\mathrm{ST}}=3.77(1.05) ; F(1 ; 1273)=46.7 ; p<.001$; partial $\eta^{2}=.035$. In addition, immigrants identified with their country of residence stronger than stayers: $M(S D)_{\mathrm{IM}}=3.69(.97) v s . M(S D)_{\mathrm{ST}}=3.26(1.03) ; F(1 ; 1279)=32.1, p<$ 0.001 ; partial $\eta^{2}=.025$. However, immigrants reported a higher level of perceived discrimination than $s t a y e r s: M(S D)_{\mathrm{IM}}=1.89(.72)$ vs. $M(S D)_{\mathrm{ST}}=1.69(.69) ; F(1 ; 1263)=5.36, p=.021$, partial $\eta^{2}=.004$.

To compare immigrants and stayers in SES, education and occupational status in the two populations were compared controlling for age, gender, marital status, level of religiosity, and Jewish ethnicity. The results demonstrated that stayers had a higher level of education than immigrants: $M(S D)_{\mathrm{ST}}=2.85(.42) v s . M(S D)_{\mathrm{IM}}=2.66(.59) ; F(1 ; 1271)=50.0 ; p<.001 ;$ partial $\eta^{2}=.038$. A similar result was obtained for occupational status: $M(S D)_{\mathrm{ST}}=4.37(1.54) v s . M(S D)_{\mathrm{IM}}=3.56(1.60) ; F(1 ; 1275)=66.8 ; p<.001 ;$ partial $\eta^{2}=$ .050 .

\section{Structural equation modeling}

The research hypotheses related to connections between the study variables were tested separately among immigrants and stayers by Structural Equation Modeling (Mplus Version 7, Muthén \& Muthén, 2012). The full-information maximum likelihood estimation with robust standard errors was used to cope with missing data (Little \& Rubin, 2019). Observed rather than latent variables were included in the model because the internal reliability of all scales was high (Kelloway, 2014). The direct and indirect effects were tested simultaneously using the bootstrapping method, with 2000 re-samples with a $95 \%$ confidence interval. Fig. 1 presents the research model for immigrants and stayers.

\section{Immigrants}

The goodness of fit indexes did not meet the criteria for model fit: $\chi^{2}(6)=25.0, p<.001 ; R M S E A(C I)=.091(.056 ; .128)$; CFI $=$ $.927 ; T L I=.829 ; S R M R=.054$. The examination of modification indexes based on $\chi^{2}$ tests (Muthén \& Muthén, 2012; Wuensch, 2012), revealed that the addition of a path connecting occupational status to perceived discrimination might significantly improve the model. After the addition, the model demonstrated an excellent fit: $\chi^{2}(4)=6.59, p=.102 ; R M S E A(C I)=.040(.000 ; .093) ; C F I=.990 ; T L I=$ $.964 ;$ SRMR $=.025$. The model explained $25 \%$ of the variance in SWL. Fig. 2 presents statistically significant connections between variables in the model.

Confirming the first hypothesis, the direct effects of both elements of SES on SWL were significant: for education $(\beta=.10, p=.044)$ and occupational status $(\beta=.14, p=.005)$. Confirming the second hypothesis, the direct effect of identification with Israel on SWL was significant $(\beta=.27, p<.001)$ and confirming the third hypothesis, a direct effect of identification with the immigrants' country of origin on SWL was not significant $(\beta=.04, p=.322)$. Finally, confirming the fourth hypothesis, a direct effect of perceived

Table 2

Means, Standard Deviations, and Bivariate Correlations.

\begin{tabular}{|c|c|c|c|c|c|c|c|}
\hline Variables: Immigrants/ Stayers & 1 & 2 & 3 & 4 & 5 & 6 & $M(S D)$ \\
\hline 1 SWL & - & $.22^{* * *}$ & $.12^{* *}$ & $-.16^{* * *}$ & $.07^{*}$ & .06 & $\begin{array}{l}3.77 \\
(1.05)\end{array}$ \\
\hline 2 Identification with Israel/ Russia & $.40 * * *$ & - & $.10 *$ & $-.15^{* * *}$ & -.01 & -.02 & $\begin{array}{l}3.26 \\
(1.03)\end{array}$ \\
\hline $\begin{array}{l}3 \text { Identification with the country of origin/ Jews in } \\
\text { Russia }\end{array}$ & -.05 & $-.19^{* * *}$ & - & $.14 * * *$ & $.13^{* * *}$ & -.02 & $\begin{array}{l}4.02 \\
(1.01)\end{array}$ \\
\hline 4 Perceived discrimination & $-.36 * * *$ & $-.35 * * *$ & .09 & - & -.06 & -.02 & $1.69(.69)$ \\
\hline 5 Occupational status & $.28 * * *$ & $.25 * * *$ & -.07 & $-.20 * * *$ & - & $.28^{* * *}$ & $\begin{array}{l}4.37 \\
(1.54)\end{array}$ \\
\hline 6 Education & $.21^{* * *}$ & $.18^{* * *}$ & -.09 & -.06 & $.39 * * *$ & - & $2.85(.42)$ \\
\hline$M(S D)$ & $\begin{array}{l}4.08 \\
(1.24)\end{array}$ & $\begin{array}{l}3.69 \\
(.97)\end{array}$ & $\begin{array}{l}2.61 \\
(1.01)\end{array}$ & $\begin{array}{l}1.89 \\
(.72)\end{array}$ & $\begin{array}{l}3.56 \\
(1.60)\end{array}$ & $\begin{array}{l}2.66 \\
(.59)\end{array}$ & - \\
\hline
\end{tabular}

Note: Immigrants are below diagonal; stayers - above. ${ }^{*} p<.05 .{ }^{* *} p<.01 .{ }^{* * *} p<.001$. 


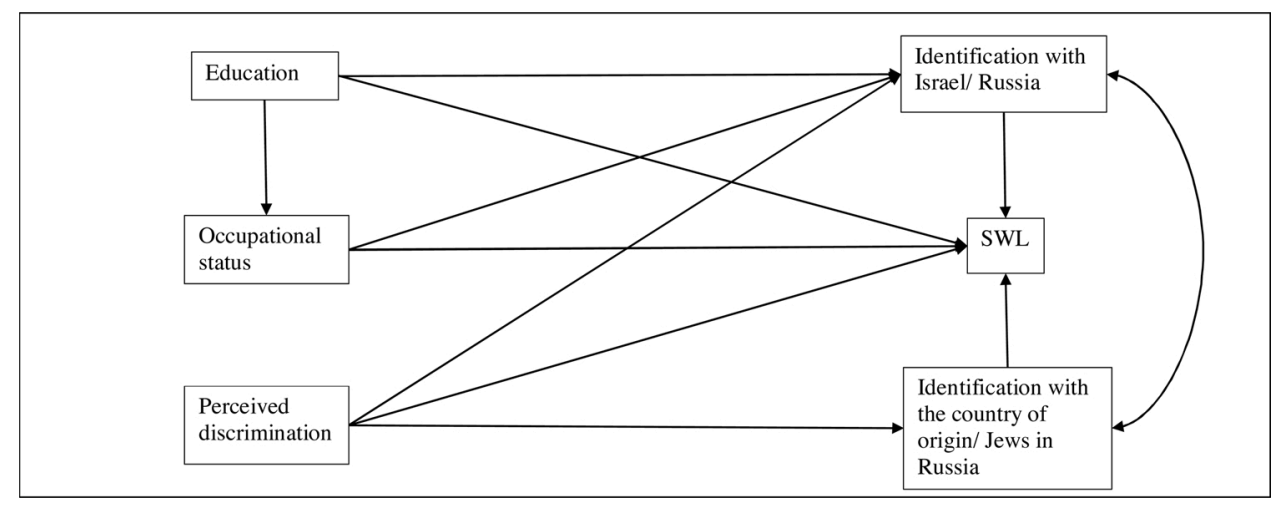

Fig. 1. The Research Model: Immigrants/ Stayers.

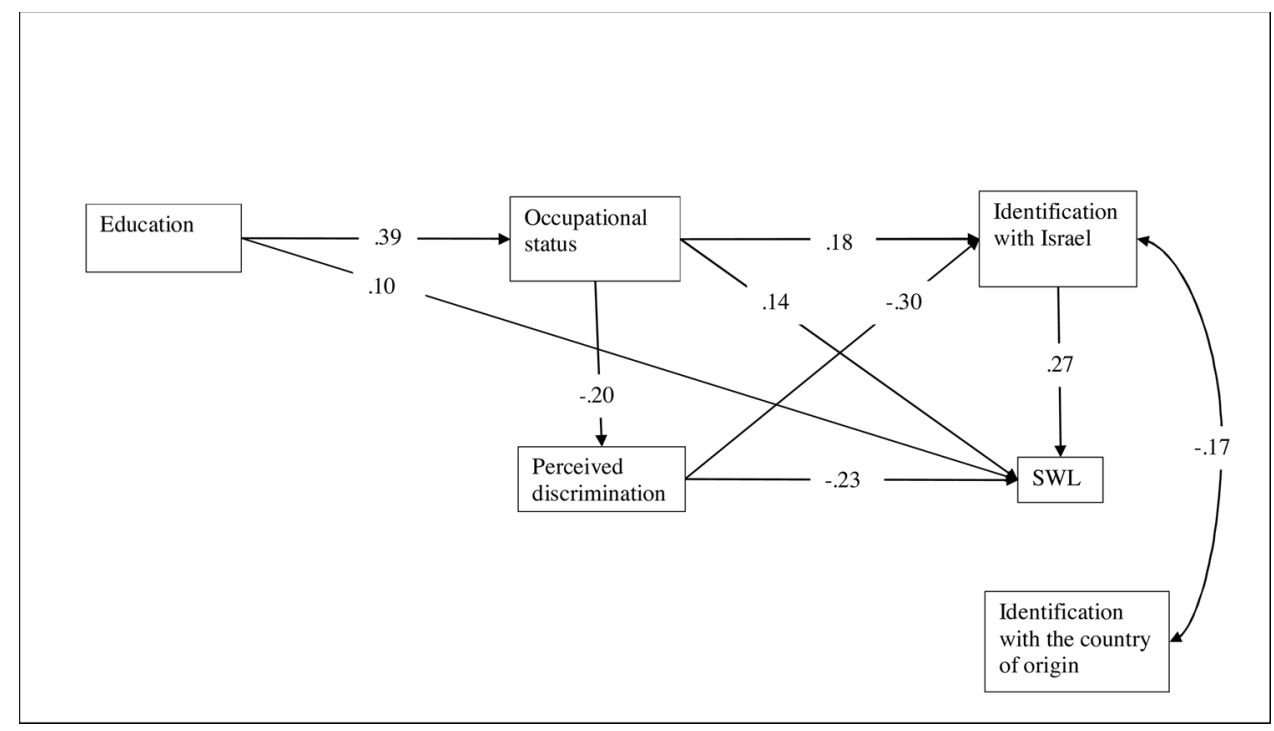

Fig. 2. Immigrants: Statistically Significant Connections Between Variables.

Note: The figure presents standardized direct effects. All paths presented are significant at $\mathrm{p}<.05$ level or higher.

discrimination on SWL was significant $(\beta=-.23, p<.001)$.

Confirming the fifth hypothesis, a direct effect of perceived discrimination on identification with Israel was significant $(\beta=-.30, p<$ $.001)$, as well as an indirect effect of perceived discrimination on SWL through its connection to identification with Israel ( $\beta=-.082 ; p<$ $.000)$. A direct effect of perceived discrimination on identification with the country of origin was not significant $(\beta=.08, p=.080)$, as was an indirect effect of perceived discrimination on SWL through its connection to identification with the country of origin $(\beta=.004$, $p=.390$ ).

Partly confirming the sixth hypothesis, a direct effect of occupational status on identification with Israel was significant $(\beta=.18, p$ $<.001)$, as well as an indirect effect of occupational status on SWL through its connection to identification with Israel ( $\beta=.048 ; p=$ $.001)$. Besides, a direct effect of occupational status on perceived discrimination was significant $(\beta=-.20, p<.001)$, as well as an indirect effect of occupational status on SWL through its connection to perceived discrimination $(\beta=.047 ; p=.001)$. Direct connections between education and identification with Israel and perceived discrimination were not significant; the indirect effects of education on SWL through these variables were also not significant. However, education positively affected SWL indirectly through its connection to occupational status $(\beta=.053 ; p=.007)$.

\section{Stayers}

The goodness of fit indexes did not meet the criteria for model fit: $\chi^{2}(5)=29.4, p=.001 ; R M S E A(C I)=.073(.049 ; 1.000)$; CFI $=$ $.890 ; T L I=.691 ; S R M R=.031$. The examination of modifications indexes based on $\chi^{2}$ tests (Muthén \& Muthén, 2012; Wuensch, 2012), revealed that the addition of paths connecting occupational status and education to identification with Jews in Russia might significantly improve the model. After the addition, all indexes indicated an excellent model fit: $\chi^{2}(3)=6.60, p=.086 ; R M S E A(C I)=.036$ 
(.000; .075); $C F I=.984 ; T L I=.954 ; S R M R=.017$. The model explained $9 \%$ of the variance in SWL among stayers. Fig. 3 presents statistically significant connections between variables in the model.

Partly confirming the first hypothesis, a direct effect of education on SWL was significant $(\beta=.07, p=.030)$; however, the effect of occupational status on SWL was not significant $(\beta=.02, p=.313)$. Confirming the second hypothesis, the direct effect of identification with Russia on SWL was significant $(\beta=.19, p<.001)$ and confirming the third hypothesis, a direct effect of identification with Jews in Russia on SWL was also significant $(\beta=.12, p<.001)$. Finally, confirming the fourth hypothesis, a direct effect of perceived discrimination on SWL was significant $(\beta=-.15, p<.001)$.

Confirming the fifth hypothesis, a direct effect of perceived discrimination on identification with Russia was significant ( $\beta=-.15, p$ $<.001)$, as well as an indirect effect of perceived discrimination on SWL through its connection to identification with Russia $(\beta=-.029$; $p<.000)$. In addition, a direct effect of perceived discrimination on identification with Jews in Russia was significant $(\beta=.16, p<$ $.001)$, as was an indirect effect of perceived discrimination on SWL through its connection to identification with Jews in Russia ( $\beta=$ $.019, p=.003)$. However, the total indirect effect of perceived identification on SWL was not significant $(\beta=-.010, p=.376)$.

The direct effects of both elements of SES on identification with Russia were not significant: for occupational status ( $\beta=-.03, p=$ .264 ) and education $(\beta=-.03, p=.455)$. Accordingly, the indirect effects of these variables on SWL through their connections to identification with Russia were also not significant $(\beta=-.007 ; p=.273 ; \beta=-.002 ; p=.389)$. Thus, the sixth hypothesis was not confirmed for stayers. However, education was directly connected to identification with Jews in Russia $(\beta=.14, p<.001)$, and, consequently, education affected SWL indirectly through its connection to identification with Jews in Russia ( $\beta=.010 ; p=.006)$. Finally, a direct effect of occupational status on identification with Jews in Russia was significant $(\beta=.15, p<.001)$, as was an indirect effect of occupational status on SWL through its connection to identification with Jews in Russia $(\beta=.018, p=.004)$.

\section{Discussion}

In the present study, we aimed to advance the existing knowledge on the psychological well-being of immigrants. To achieve this goal, we 1) tested the morbidity $v s$. salutary immigration hypotheses by comparing the psycho-social characteristics of immigrants and stayers; 2) tested a resource model of well-being among immigrants and stayers by investigating the role of different resources and stressors in predicting SWL. Below, we discuss the results obtained along the two lines of investigation.

\section{Testing the morbidity and salutary immigration hypotheses}

The results obtained provided a complex picture regarding the psychological well-being of immigrants compared to stayers. On the one hand, immigrants, on average, reported a higher SWL than stayers, thus indicating that in general, the psychological well-being of immigrants was higher than that of stayers. In addition, immigrants reported stronger identification with their country of residence. However, other variables related to well-being were more problematic among immigrants compared to stayers. First, both components of socio-economic status - education and occupational status - were lower among immigrants compared to stayers. This finding indicates that immigrants from the FSU experience difficulties adjusting to the education system and job market in Israel (Amit, 2012; Chachashvili-Bolotin, 2011). Second, immigrants reported a higher level of perceived discrimination than stayers, which indicates that immigrants from the FSU feel less accepted by the majority society in Israel than do Jews staying in Russia. Thus, the results obtained indicated that immigration is neither unequivocally salutogenic nor pathogenic; rather, it is a complex process that brings both gains and losses to immigrants.

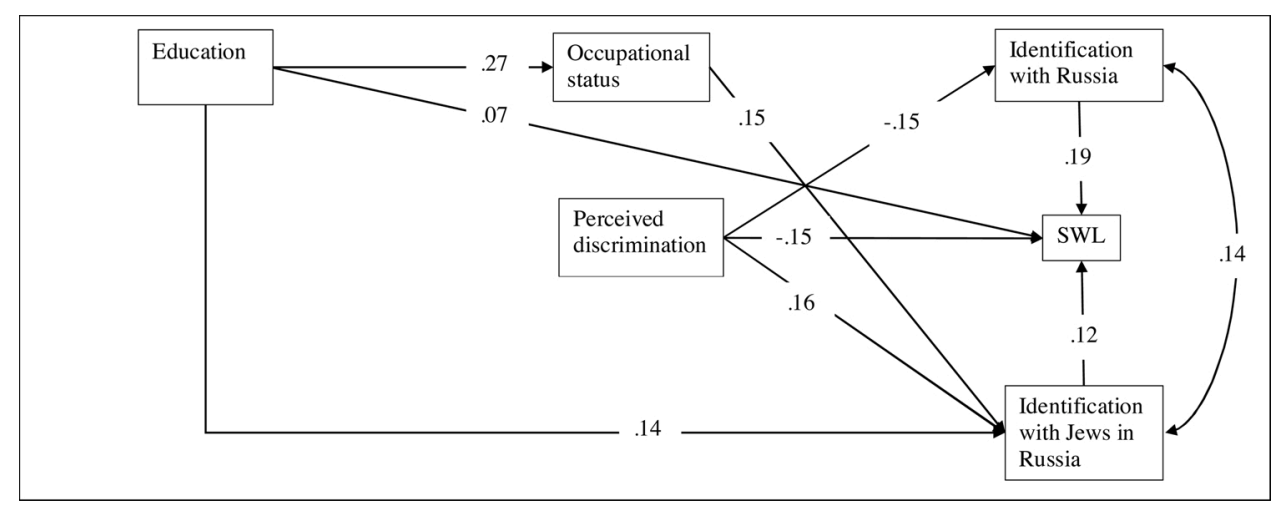

Fig. 3. Stayers: Statistically Significant Connections Between Variables.

Note: The figure presents standardized direct effects. All paths presented are significant at $\mathrm{p}<.05$ level or higher. 
Testing a resource model of well-being among immigrants and stayers

\section{Direct effects}

Our findings corroborated the results of previous studies demonstrating that tangible resources (socio-economic status), social resources (group identifications), and social stressors (perceived discrimination) directly affect the psychological well-being of both immigrants and stayers. However, we also found substantial differences between immigrants and stayers. For instance, both components of SES (education and occupational status) positively affected SWL among immigrants; however, the effect of occupational status on SWL was not significant among stayers. This difference may be explained if we recall that occupational status is strongly connected to income (Barger et al., 2009; Sobel et al., 2019), and the effect of income on psychological well-being is usually weaker in groups with a higher level of income (Lyubomirsky et al., 2005; Myers, 2000). In the present study, stayers had a higher occupational status than immigrants, which may explain why among stayers, occupational status had a smaller impact on psychological well-being than among immigrants.

Among both immigrants and stayers, stronger identification with the country of residence was associated with a higher level of SWL. This finding indicates that the country of residence is an important resource helping its citizens satisfy their needs and thus promoting their psychological well-being (Amit, 2012). In addition, among stayers, identification with the ethnic minority group was directly connected to SWL, while among immigrants, identification with the country of origin was not connected to SWL. To explain the difference between immigrants and stayers, we may assume that the ethnic minority group and the immigrants' country of origin differ in their ability to provide social support to their members. Despite the transnational connections, the opportunities for immigrants to receive social support from their country of origin is limited. Thus, identification with this country does not improve the psychological well-being of immigrants. On the other hand, the Jewish community in Russia is highly organized and has numerous community institutions (Kantor Center for the Study of Contemporary European Jewry, 2019). Therefore, identification with this group may provide its members with much needed social support and promote their psychological well-being.

Finally, among both immigrants and stayers, perceived discrimination was directly associated with decreased psychological wellbeing. This finding replicates the results of previous studies and indicates that discrimination is a universal stressor negatively affecting the psychological well-being of immigrants and ethnic minorities (Berry \& Hou, 2017; Berry, 2017; Ward et al., 2018). However, this finding is important because, in the present study, the level of perceived discrimination was low among both immigrants and stayers. Thus, the results obtained demonstrate that the negative effect of perceived discrimination on psychological well-being is preserved even when the level of this stressor is low.

\section{Indirect effects}

Most previous studies focused on the direct effects of resources and stressors on psychological well-being. In the present study, we also examined indirect effects; i.e., we investigated how the resources and stressors might affect the psychological well-being of immigrants and stayers through their connections to other resources and stressors. We revealed several indirect effects of occupational status and perceived discrimination on psychological well-being among immigrants and stayers.

\section{Indirect effects of occupational status on psychological well-being}

First, we found a positive indirect effect of occupational status on psychological well-being through its negative connection to perceived discrimination among immigrants. Previous studies have demonstrated that the socio-economic status of local people affects their attitudes towards immigrants (Tartakovsky \& Walsh, 2019). Therefore, the negative connection between occupational status and perceived discrimination may indicate that immigrants who achieve a higher occupational status in the receiving country suffer less from discrimination because local people with whom they are working have a more positive attitude towards immigrants. Second, we found a positive indirect effect of occupational status on psychological well-being through its positive connection to identification with the country of residence among immigrants. The positive connection between occupational status and identification with the country of residence among immigrants indicates that immigrants who are better professionally adjusted in the receiving country consider this country in a more positive light and, therefore, more strongly identify with the country. Finally, positive indirect effects of education and occupational status on psychological well-being through their positive connections to ethnic identification were found among stayers. The positive connections between education and occupational status and Jewish identification among stayers may probably be explained by a high proportion of Jews having high education and high occupational status. The high proportion of Jews in occupations requiring high education probably permits members of this ethnic minority group to meet each other and thus develop stronger ethnic identification, which, in turn, increases their psychological well-being.

\section{Indirect effects of perceived discrimination}

Among both immigrants and stayers, we found a negative indirect effect of perceived discrimination on psychological well-being through its negative connection to identification with the country of residence. The negative connection between perceived discrimination and identification with the country of residence corroborated the rejection-disidentification model among immigrants. In addition, among stayers, we found a positive indirect effect of perceived discrimination on psychological well-being through its positive connection to ethnic identification. The positive connection between perceived discrimination and ethnic identification corroborated the rejection-identification model among stayers (Bobowik et al., 2017; Eccleston \& Major, 2006; Jasinskaja-Lahti et al., 2009).

The found difference between stayers and immigrants may be related to the differences in the connection between identification 
with the country of origin and ethnic minority group with psychological well-being. As mentioned above, stronger identification with the ethnic minority group was associated with a higher level of SWL among stayers. However, no connection was found between SWL and identification with the country of origin among immigrants. Therefore, among stayers, persons experiencing discrimination sense that identification with the ethnic minority group can shelter them from rejection by the majority population because identification with the ethnic minority group increases their psychological well-being. Among immigrants, identification with the country of origin cannot provide such shelter because it does not increase the psychological well-being. The results obtained in the present study help to understand the inconsistencies found when testing the rejection-identification model in different populations (Bobowik et al., 2017). Specifically, our findings suggest that the rejection-identification pattern of connections between perceived discrimination and identification with a minority group exists only when the minority group constitutes a source of social support for its members; i.e., identification with this group is a resource that promotes the psychological well-being of the group members.

\section{Limitations and suggestions for further research}

The present study has several limitations. First, the study was cross-sectional. Therefore, we should be careful considering causality because connections between some variables may be reciprocal. For instance, immigrants with a higher level of well-being may have more affective-cognitive resources to achieve a higher SES, to develop a stronger sense of belonging to the larger society, and to better cope with discrimination (Lönnqvist et al., 2015). Therefore, further studies using longitudinal pre-post-migration design are required. Second, we investigated immigrants from the FSU only in Israel, while substantial numbers of Jews from the FSU have also emigrated to the US and Germany (Silbereisen et al., 2016). Including these immigrant groups in further studies may distinguish between general and country-specific factors affecting the immigrants' well-being and group identifications. Furthermore, the present study focused on Jews. Comparing immigrants and stayers belonging to other ethnic groups in the FSU (e.g., Germans, Finns, and Greeks) may further advance our understanding of the immigration processes among diaspora immigrants. Finally, an important limitation of the present study is related to the scale measuring identification with the country of residence, in which scalar invariance was not established. Although the difference between immigrants and stayers in identification with the country of residence was of medium size, it is still probable that the difference found was due to a scale's bias. Further studies comparing immigrants and stayers may use other measures of social attachment, e.g., scales measuring the sense of belonging (Amit, 2012).

\section{Conclusion}

The present study is one of the few that tested the salutary and morbidity immigration hypotheses comparing the psycho-social characteristics of immigrants and stayers. The findings indicated that immigration is a mixed blessing for the studied group of immigrants - it is salutary in some aspects but onerous in others. Our research demonstrated the usefulness of a resource model in analyzing the effects of different variables on psychological well-being among immigrants and stayers. In addition to corroborating the results of previous studies regarding the direct effects of SES, perceived discrimination, and group identifications on psychological well-being, the present study revealed important indirect effects of these variables on psychological well-being. Thus, the present study demonstrated that resources and stressors might affect psychological well-being of immigrants and ethnic minorities through their influence on other resources and stressors. Finally, the present studs advanced our understanding of the rejection-disidentification and rejection-identification models, explaining the connections between perceived discrimination, group identifications, and psychological well-being among immigrants and stayers.

\section{Declaration of Competing Interest}

The authors report no conflicts of interest.

\section{Acknowledgements}

The study was partly supported by a grant from Leonid Nevzlin Research Center for Russian and East European Jewry at the Hebrew University of Jerusalem. Israel Science Foundation Grant 244/15.

\section{Appendix A. Supplementary data}

Supplementary material related to this article can be found, in the online version, at doi:https://doi.org/10.1016/j.ijintrel.2020. 11.012.

\section{References}

Amit, K. (2012). Social integration and identity of immigrants from western countries, the FSU and Ethiopia in Israel. Ethnic and Racial Studies, 35(7), 1287-1310. Bak-Klimek, A., Karatzias, T., Elliott, L., \& Maclean, R. (2015). The determinants of well-being among international economic immigrants: A systematic literature review and meta-analysis. Applied Research in Quality of Life, 10(1), 161-188. 
Baltatescu, S. (2005). Subjective well-being of immigrants in Europe And their evaluation of societal conditions. An exploratory study. In L. Pop, \& C. Matiuţă (Eds.), European identity and free movement of persons in Europe (pp. 128-143). Oradea: University of Oradea Publishing House.

Barger, S. D., Donoho, C. J., \& Wayment, H. A. (2009). The relative contributions of race/ethnicity, socio-economic status, health, and social relationships to life satisfaction in the United States. Quality of Life Research, 18(2), 179-189.

Bartram, D. (2011). Economic migration and happiness: Comparing immigrants' and natives' happiness gains from income. Social Indicators Research, 103(1), 57-76.

Berry, J. W. (2017). Theories and models of acculturation. In S. J. Schwartz, \& J. Unger (Eds.), Oxford handbook of acculturation and health (pp. 15-27). Oxford University Press.

Berry, J. W., \& Hou, F. (2017). Acculturation, discrimination, and well-being among second generation of immigrants in Canada. International Journal of Intercultural Relations, 61, 29-39.

Bobowik, M., Martinovic, B., Basabe, N., Barsties, L. S., \& Wachter, G. (2017). 'Healthy' identities? Revisiting rejection-identification and rejection-disidentification models among voluntary and forced immigrants. European Journal of Social Psychology, 47(7), 818-831.

Bowe, A. G. (2017). The immigrant paradox on internalizing symptoms among immigrant adolescents. Journal of Adolescence, 55 , $72-76$.

Calvo, R., \& Cheung, F. (2018). Does money buy immigrant happiness? Journal of Happiness Studies, 19(6), 1657-1672.

Chachashvili-Bolotin, S. (2011). Educational achievements and study patterns of immigrants from the Former Soviet Union in Israeli secondary schools. Canadian Review of Art Education Research and Issues / Revue Canadienne de Recherches et Enjeux En Ã\%oducation Artistique, 97, 84-96.

Diener, E. R., Emmos, R., Larsen, R., \& Griffin, S. (1985). The satisfaction with life scale. Journal of Personality Assessment, 49(1), 71-75.

Eccleston, C. P., \& Major, B. N. (2006). Attributions to discrimination and self-esteem: The role of group identification and appraisals. Group Processes \& Intergroup Relations, 9, 147-162.

Hendriks, M. (2015). The happiness of international migrants: A review of research findings. Migration Studies, 3(3), 343-369.

Hobfoll, S. E. (2002). Social and psychological resources and adaptation. Review of General Psychology, 6(4), $307-324$.

Jasinskaja-Lahti, I., Liebkind, K., \& Solheim, E. (2009). To identify or not to identify? National disidentification as an alternative reaction to perceived ethnic discrimination. Applied Psychology: An International Review, 58, 105-128.

Kahan-Strawczynski, P., Levi, D., \& Konstantinov, V. (2010). Immigrant youth in Israel - The current situation. Myers-JDC-Brookdale Institute. https://brookdale.jdc.org. il/wp-content/uploads/2018/01/561-10-ImmigrantYouth-REP-HEB.pdf.

Kantor Center for the Study of Contemporary European Jewry. (2019). Russian federation. http://www.kantorcenter.tau.ac.il/russian-federation-0.

Kelloway, E. K. (2014). Using MPlus for structural equation modeling: A researcher's guide. Sage Publications.

Kirmanoglu, H., \& Baslevent, C. (2014). Life satisfaction of ethnic minority members: An examination of interactions with immigration, discrimination, and citizenship. Social Indicators Research, 116, 173-184.

Little, R. J., \& Rubin, D. B. (2019). Statistical analysis with missing data (Vol. 793). John Wiley \& Sons.

Lönnqvist, J.-E., Leikas, S., Mähönen, T. A., \& Jasinskaja-Lahti, I. (2015). The mixed blessings of migration: Life satisfaction and self-esteem over the course of migration. European Journal of Social Psychology, 45, 496-514.

Lyubomirsky, S., Sheldon, K. M., \& Schkade, D. (2005). Pursuing happiness: The architecture of sustainable change. Review of General Psychology, 9(2), 111-131.

Massey, D. A. (2002). Synthetic theory of international migration. In V. Iontsev (Ed.), The world in the mirror of international migration (vol. 10, pp. 143-153). Moscow: MAX Press.

Mirsky, J., Kohn, R., Levav, I., Grinshpoon, A., \& Ponizovsky, A. M. (2008). Psychological distress and common mental disorders among immigrants: Results from the Israeli-based component of the World Mental Health Survey. The Journal of Clinical Psychiatry, 69(11), $1715-1720$.

Muthén, L. K., \& Muthén, B. O. (2012). MPlus user's guide, 7th edition. Los Angeles, CA.

Myers, D. G. (2000). The funds, friends, and faith of happy people. The American Psychologist, 55(1), 56.

Neto, F. (2001). Satisfaction with life among adolescents from immigrant families in Portugal. Journal of Youth and Adolescence, $30(1)$, 53-67.

Phinney, J. S., Horenczyk, G., Liebkind, K., \& Vedder, P. (2001). Ethnic identity, immigration, and well-being: An interactional perspective. The Journal of Social Issues, 57(3), 493-510.

Phinney, J. S., Madden, T., \& Santos, L. J. (1998). Psychological variables as predictors of perceived ethnic discrimination among minority and immigrant adolescents. Journal of Applied Social Psychology, 28(11), 937-953.

Pinquart, M., \& Sörensen, S. (2000). Influences of socio-economic status, social network, and competence on subjective well-being in later life: A meta-analysis. Psychology and Aging, 15(2), 187.

Raijman, R., \& Geffen, R. (2018). Sense of belonging and life satisfaction among post-1990 immigrants in Israel. International Migration, 56(3), $142-157$.

Roccas, S. (2003). The effects of status on identification with multiple groups. European Journal of Social Psychology, 33(3), 351-366.

Salas-Wright, C. P., Vaughn, M. G., Schwartz, S. J., \& Córdova, D. (2016). An "immigrant paradox" for adolescent externalizing behavior? Evidence from a national sample. Social Psychiatry and Psychiatric Epidemiology, 51(1), 27-37.

Sam, D. L., Vedder, P., Liebkind, K., Neto, F., \& Virta, E. (2008). Immigration, acculturation and the paradox of adaptation in Europe. The European Journal of Developmental Psychology, 5(2), 138-158.

Silbereisen, R. K., Titzmann, P. F., \& Shavit, Y. (2016). The challenges of diaspora migration: Interdisciplinary perspectives on Israel and. Germany: Routledge.

Smith, T. B., \& Silva, L. (2011). Ethnic identity and personal well-being of people of color: A meta-analysis. Journal of Counseling Psychology, 58, 42-60.

Sobel, I., Semyonov, M., \& Lewin-Epstein, N. (2019). The dynamic relationship between wealth and subjective well-being among mid-life and older adults in Israel. In G. Brulé, \& C. Suter (Eds.), Wealth(s) and subjective well-being (pp. 415-442). Springer Nature.

Stevens, G., \& Featherman, D. L. (1981). A revised socio-economic index of occupational status. Social Science Research, 10(4), $364-395$.

Tartakovsky, E., \& Walsh, S. D. (2019). Are some immigrants more equal than others? Applying a threat-benefit model to understanding the appraisal of different immigrant groups by the local population. Journal of Ethnic and Migration Studies. https://doi.org/10.1080/1369183X.2019.1565402 (published online).

Tartakovsky, E., Patrakov, E., \& Nikulina, M. (2017). The emigration intentions of Russian Jews: The role of sociodemographic variables, social networks, and satisfaction with life. East European Jewish Affairs, 47(2-3), 242-254.

The State of Israel. (1970). (1950/1954/1970). The law of return. https://www.knesset.gov.il/laws/special/eng/return.htm.

UNDP, United Nations Development Programme. (2019). Human development reports. http://hdr.undp.org/en/content/2019-human-development-index-ranking.

Verkuyten, M., \& Yildiz, A. A. (2007). National (dis) identification and ethnic and religious identity: A study among Turkish-Dutch Muslims. Personality \& Social Psychology Bulletin, 33(10), 1448-1462.

Walsh, S. D., \& Tartakovsky, E. (2011). The relationship between different components of national identities and psycho-social adjustment among high-school adolescent immigrants from Russia and Ukraine in Israel. The European Journal of Developmental Psychology, 8(4), 452-472.

Ward, C., Gale, J., Staerklé, C., \& Stuart, J. (2018). Immigration and multiculturalism in context: A framework for psychological research. The Journal of Social Issues, 74(4), 833-855.

Wei, M., Heppner, P. P., Mallen, M. J., Ku, T., Liao, K. Y., \& Wu, T. (2007). Acculturative stress, perfectionism, years in the United States, and depression among Chinese international students. Journal of Counseling Psychology, 54(4), 385-394.

Wuensch, K. L. (2012). An introduction to path analysis. http://core.ecu.edu/psyc/wuenschk/MV/SEM/Path.pdf. 